\title{
The crystal growth kinetics of alpha calcium sulfate hemihydrate in concentrated $\mathrm{CaCl}_{2}-\mathrm{HCl}$ solutions
}

\author{
Thomas Feldmanna (thomas.feldmann@mail.mcgill.ca), \\ George P. Demopoulos ${ }^{\mathrm{a} *}$ (george.demopoulos@mcgill.ca) \\ ${ }^{a}$ McGill University, 3610 University Street, Montreal, QC, H3A 2B2, Canada \\ Phone: +1 514-398-2046 \\ Fax: +1 514-398-4492 \\ * Corresponding author
}

\begin{abstract}
The crystal growth kinetics of calcium sulfate $\alpha$-hemihydrate $(\alpha-\mathrm{HH})$ in nearly constant supersaturated $\mathrm{HCl}-\mathrm{CaCl}_{2}$ solutions were investigated. Two types of solutions were used, the first had a low $\mathrm{HCl}(1.4$ $\mathrm{mol} / \mathrm{L})$ and high $\mathrm{CaCl}_{2}(2.8 \mathrm{~mol} / \mathrm{L})$ concentration and the second had a high $\mathrm{HCl}(5.6 \mathrm{~mol} / \mathrm{L})$ and low $\mathrm{CaCl}_{2}(0.7 \mathrm{~mol} / \mathrm{L})$ concentration. These conditions were chosen to represent the first and last stage of a newly developed stage-wise $\mathrm{HCl}$ regeneration process. The seeded growth experiments were carried out in a stirred, temperature controlled semi-batch reactor in which supersaturation was kept constant by simultaneous addition of $\mathrm{CaCl}_{2}$ and $\mathrm{Na}_{2} \mathrm{SO}_{4}$ solutions. The influence of the following parameters on $\alpha-\mathrm{HH}$ crystal growth was studied: temperature $\left(70-95^{\circ} \mathrm{C}\right)$, specific power input of stirring $(0.02-1.29$ $\mathrm{W} / \mathrm{kg}$ ) and equimolar inflow rate of $\mathrm{CaCl}_{2}$ and $\mathrm{Na}_{2} \mathrm{SO}_{4}(0-0.6 \mathrm{~mol} / \mathrm{h})$. The crystal growth rate was derived from particle size distribution measurements made with the laser light diffraction technique. It was found that the surface area normalized crystal growth rate increased linearly with the molar inflow rate up to $0.3 \mathrm{~mol} / \mathrm{h}$, at higher inflow rates no further increase of the growth rate was observed. Temperature and specific power input, within the investigated ranges, did not show a marked effect on the growth rate, attributable to a diffusion/adsorption controlled growth process. An interesting finding of the present research is the establishment of a positive relationship between the narrowing of the width of the particle size distribution with increasing crystal growth rate. The results show that the resulting particle size distribution is positively related to the reagent inflow rate, a finding that can be applied to the industrial design and scale-up of the $\alpha-\mathrm{HH}$ crystallization/ $\mathrm{HCl}$ regeneration process.
\end{abstract}

Keywords: A2 Industrial crystallization, A2 Seed crystals, A2 Constant supersaturation, B1 Calcium sulfate alpha hemihydrate, B1 Hydrochloric acid, B1 Calcium chloride

\section{Introduction}

Calcium sulfate can exist in five phases [1], one of which is calcium sulfate hemihydrate (HH) that has two crystal forms: the $\alpha$ - and $\beta$-form. The $\alpha$-form is an especially valuable building material due to its enhanced mechanical properties after rehydration. The strength of the obtained plaster and the amount of water needed for setting depends on the particle size distribution [2, 3]. For example, the modulus of rupture of commercial $\alpha$-hemihydrate was reported to be approximately $2 \mathrm{MN} / \mathrm{m}^{2}$ higher than that of the more commonly used $\beta$-hemihydrate. The latter material is produced normally by dry calcination while the former requires the presence of water either as vapor (steam) or liquid phase as such they have different crystallization behavior than typical competing polymorphic systems [4]. In this context it should be added that both forms of hemihydrate, namely the $\alpha$ and $\beta$ ones have the same crystal 
structure but the alpha form having superior plaster properties due to its potential to form well developed crystals with fewer cracks and pores [5]. Hence the importance of understanding and controlling the crystal growth kinetics of calcium sulfate $\alpha$-hemihydrate as studied in this work.

So far the widespread use of $\alpha-\mathrm{HH}$ has been affected negatively by the higher cost of its production. Therefore the study of alternative production methods for this material is important. The most commonly used process is the conversion of calcium sulfate dihydrate in an autoclave at temperatures well above $100^{\circ} \mathrm{C}$ with high steam partial pressures [6]. In such a process natural or synthetic calcium sulfate dihydrate is either pressed into briquettes [6-8] or an aqueous slurry is prepared [9], which typically have to be treated for several hours.

Another option to produce $\alpha-\mathrm{HH}$ is by conversion from dihydrate via its treatment in concentrated salt solutions at temperatures between $85^{\circ} \mathrm{C}$ and $110^{\circ} \mathrm{C}$ at atmospheric pressure for several hours [10-13]. Solutions that are typically used as medium in which $\mathrm{DH}$ is converted to $\alpha-\mathrm{HH}$ contain salts of high solubility having as a result an elevated boiling point [14], for example $\mathrm{CaCl}_{2}$, or mixed aqueousorganic solutions have been suggested for such use recently [15].

Another approach to the production of $\alpha-\mathrm{HH}$ is taken with the Omega process [16,17], in which $\mathrm{SO}_{2}$ gas from power plant gases is contacted with a $\mathrm{Ca}(\mathrm{OH})_{2}$ solution. This results in a calcium sulfite slurry that is continuously fed to an autoclave and mixed with sulfuric acid solution to adjust the $\mathrm{pH}$ to a controlled end point. The calcium sulfite is then dissolved and precipitated as calcium sulfate $\alpha$ hemihydrate under oxidizing conditions, which are achieved by air injection.

However, more recently the direct production of $\alpha-\mathrm{HH}$ by reacting solutions that contain calcium and sulfate ions at appropriate temperature conditions [18-20] was investigated. It was suggested to react both solutions in the presence of a concentrated $\mathrm{CaCl}_{2}$ electrolyte. Temperatures around $80^{\circ} \mathrm{C}$ are favorable for the formation of $\alpha-\mathrm{HH}$ [19]. Previous work undertaken in our laboratory in connection to $\alpha-\mathrm{HH}$ production sought simultaneously to produce high strength $\mathrm{HCl}$ acid $[21,22]$ thus allowing the cost-effectiveness of the new process via its integration with an extractive metallurgical operation involving leaching of ores or secondary materials such as zinc ores, rare-earth containing phosphates, or $\mathrm{TiO}_{2}$-containing slags. A key aspect of successful development of such a crystallization-based $\mathrm{HCl}$ regeneration process is stage-wise reaction of $\mathrm{H}_{2} \mathrm{SO}_{4}$ with the $\mathrm{CaCl}_{2}$ solution [21]. The design of such process can be greatly facilitated upon determination of the governing crystallization kinetics. This is the objective of the present work.

In particular, the present research focuses on the determination of the growth rate of $\alpha$-calcium sulfate hemihydrate in a seeded environment by reactive crystallization as per the following reaction [19].

$\mathrm{CaCl}_{2}+\mathrm{H}_{2} \mathrm{SO}_{4}+0.5 \mathrm{H}_{2} \mathrm{O} \rightarrow 2 \mathrm{HCl}+\mathrm{CaSO}_{4} \cdot 0.5 \mathrm{H}_{2} \mathrm{O}$

Based on previous research [19] a titration or stage-wise addition of concentrated sulfuric acid (limiting reactant) to a calcium chloride solution at $\sim 80^{\circ} \mathrm{C}$ in the presence of recycled crystals as seed allowed to maintain favorable supersaturation conditions that induced heterogeneous nucleation and growth [19]. Typically a four-stage reaction can be applied to convert a 3-4 mol/ $/ \mathrm{CaCl}_{2}$ solution to $\alpha-\mathrm{HH}$ and $\sim 5-6$ $\mathrm{mol} / \mathrm{L} \mathrm{HCl}$ upon mixing with $2.8 \mathrm{~mol}$ of $\mathrm{H}_{2} \mathrm{SO}_{4}$ at $80^{\circ} \mathrm{C}$. Therefore two conditions reflecting the steady-state environment of the first and last stage of the said hydrochloric acid regeneration/ $\alpha-\mathrm{HH}$ crystallization process were chosen to study, namely: $1.4 \mathrm{~mol} / \mathrm{L} \mathrm{HCl}$ and $2.8 \mathrm{~mol} / \mathrm{L} \mathrm{CaCl}_{2}(1.6 \mathrm{~mol} / \mathrm{kg}$, 4.1 wt. $\% \mathrm{HCl} ; 3.2 \mathrm{~mol} / \mathrm{kg}, 25$ wt. $\% \mathrm{CaCl}_{2}$ ) for the first stage; and $5.6 \mathrm{~mol} / \mathrm{L} \mathrm{HCl}$ and $0.7 \mathrm{~mol} / \mathrm{L} \mathrm{CaCl}_{2}$ $\left(6.5 \mathrm{~mol} / \mathrm{kg}, 17.8 \mathrm{wt} . \% \mathrm{HCl} ; 0.8 \mathrm{~mol} / \mathrm{kg}, 6.8 \mathrm{wt} . \% \mathrm{CaCl}_{2}\right)$ for the final stage. The growth rate was measured within the temperature range $70-95^{\circ} \mathrm{C}$. This range was chosen since below $70^{\circ} \mathrm{C}$, conversion of $\alpha-\mathrm{HH}$ to calcium sulfate dihydrate starts to occur. On the other hand at temperatures above $95^{\circ} \mathrm{C}, \alpha-$ 
$\mathrm{HH}$ has limited metastability, quickly converting to anhydrite, a condition that again is undesirable as not only leads to a loss of $\alpha-\mathrm{HH}$ but also creates crystal de-watering/separation problems. Background experimental and modeling results on calcium sulfate phase transitions in $\mathrm{CaCl}_{2}-\mathrm{HCl}$ solutions can be found in previous publications $[19,23]$.

In the past there have been numerous investigations of the growth kinetics of calcium sulfate dihydrate [24-26] observing a second order growth rate law but very few on $\alpha$-calcium sulfate hemihydrate [2729]. These studies mostly focused on dilute solutions or a different matrix than the $\mathrm{CaCl}_{2}-\mathrm{HCl}$ system investigated here. Of all the previous studies only Yang et al. [29] focused on the growth rate of $\alpha-\mathrm{HH}$ in a concentrated $\mathrm{CaCl}_{2}$ solution. But even in this study no $\mathrm{HCl}$ was involved; $\mathrm{HCl}$ is known to influence the stability/solubility of $\alpha-\mathrm{HH}[19,30]$ hence the need to include it in the context of the industrial acid regeneration application. Moreover their crystallization study was carried out in a batch reactor in which the relative supersaturation was not kept constant. More specifically, it dropped by approx. 50\% from the initial value within 20 min after the start of the experiment. In contrast industrial processes make use of continuous crystallization reactors in which steady-state (constant) supersaturation conditions prevail.

In laboratory studies like the present one, the methods used to maintain constant supersaturation usually employ spectroscopic (e.g. ATR-FTIR $[4,31,32$ ) or electrochemical in-situ monitoring (e.g. ionselective electrodes [33-35] or conductivity probes). These techniques that rely on probes, are not feasible in this context because of the very corrosive and concentrated nature of the chloride solutions: high chloride content of $7 \mathrm{~mol} / \mathrm{L}$, low $\mathrm{pH}(-1.6$ to -1.1$)$ and comparatively high temperatures, $70^{\circ} \mathrm{C}$ to $95^{\circ} \mathrm{C}$. Thus in the present work the growth kinetics of calcium sulfate $\alpha$-hemihydrate in $\mathrm{CaCl}_{2}-\mathrm{HCl}$ media were investigated by employing a semi-batch procedure as means of maintaining essentially constant supersaturation. Nearly constant supersaturation was achieved via simultaneous inflow of equimolar $\mathrm{CaCl}_{2}$ and $\mathrm{Na}_{2} \mathrm{SO}_{4}$ solutions that compensated for the precipitation of crystal lattice constituents, i.e. $\mathrm{Ca}$ and $\mathrm{SO}_{4}$ as described in [36]. This approach distinguishes the present study from previous batch type growth research involving $\alpha-\mathrm{HH}[29]$.

\section{Experimental}

\subsection{Reactor and procedure}

The crystallization experiments were carried out in a baffled, 2 L semi-batch, flat-bottom glass reactor with temperature control, a $45^{\circ}$ pitched blade impeller with three blades each at two different height levels $3 \mathrm{~cm}$ apart from each other and a peristaltic pump feed system. The experiments involved the equimolar addition of $100 \mathrm{~mL}$ of $\mathrm{CaCl}_{2}(0$ to $3 \mathrm{~mol} / \mathrm{L})$ and $200 \mathrm{~mL} \mathrm{Na} 2 \mathrm{SO}_{4}(0$ to $1.5 \mathrm{~mol} / \mathrm{L})$ solutions to $1 \mathrm{~L}$ of a background electrolyte containing calcium chloride and hydrochloric acid. The time of the experiment was set between 0.5 to $1 \mathrm{~h}$ to obtain molar inflow rates from 0.0 to $0.6 \mathrm{~mol} / \mathrm{h}$. Sodium sulfate instead of sulfuric acid was used to maintain a relatively constant acid concentration throughout the experiment hence obtaining a nearly constant solubility of $\alpha-\mathrm{HH}$ in solution [30]. All solutions were prepared from deionized water and Fisher Scientific ACS grade chemicals.

At the beginning of each experiment $30 \mathrm{~g}$ of lab made $\alpha$-hemihydrate seed was added to the reactor. For comparison of lab made seed with industrially produced $\alpha$-hemihydrate, material from Knauf Gips KG (produced from FGD gypsum) was used. Slurry samples were taken at the beginning of each experiment and then every 15 minutes and filtered with $0.2 \mu \mathrm{m}$ pore size syringe filter. The filter cake was washed with $5 \mathrm{~mL}$ of isopropanol instead of water to avoid complications from possible rehydration/transformation of the $\alpha-\mathrm{HH}$ to $\mathrm{DH}$ and stored at room temperature immersed in isopropanol 
as preservation measure until the particle size measurement was performed.

\subsection{Characterization methods}

In order to determine the growth rate, volume-based particle size distributions were measured with a Horiba Laser Scattering Particle Size Distribution Analyzer LA-920, by dispersing the solid in isopropanol, to avoid dissolution of small particles during the measurement. BET surface area measurements of the seed crystals were undertaken with a Micromeritics Tristar Surface Area Analyzer, whose results were used to calculate a surface area normalized growth rate. The crystal morphology was analyzed with a Philips XL30 FEG SEM after coating the samples with a thin layer of AuPd. XRay Powder Diffraction analysis was carried out on a Philips PW1710 powder diffractometer. $\mathrm{Cu} \mathrm{K} \alpha$ radiation with a wavelength of $1.506 \AA$ was employed. Differential Scanning Calorimetry for the identification of $\alpha-\mathrm{HH}$ was done on a Netzsch STA 449 F3 Jupiter thermal analyzer setting the heating rate to $10 \mathrm{~K} / \mathrm{min}$ under inert gas atmosphere with an Argon flow of $30 \mathrm{~mL} / \mathrm{min}$. This technique has shown to be capable of differentiating between $\alpha-\mathrm{HH}$ and $\beta-\mathrm{HH}$ [37]. Finally, filtrates were analyzed for calcium and sulfate with a Dionex ICS 5000 ion chromatograph.

To ensure reproducibility each experiment was repeated three times and arithmetic averages were employed in the analysis of the data.

\section{Results and discussion}

\subsection{Nearly constant supersaturation crystallization of $\alpha-\mathrm{HH}$}

As the investigated process is of continuous nature it was decided to adopt a constant supersaturation and seeded crystallization approach for the semi-batch experiments. In this section a typical semi-batch crystallization experiment is analyzed to ensure the obtainment/maintenance of constant supersaturation; the product is characterized to confirm that it is $\alpha-\mathrm{HH}$; and the derivation of crystal growth rates from the crystal product's particle size distribution is developed/explained.

Each experiment was initiated by starting a peristaltic pump supplying the reagents to the solution. Figure 1 shows the evolution of the calcium ion and sulfate ion concentration for a typical semi-batch crystal growth test. The calcium ion concentration remains nearly constant and the sulfate ion concentration increases only slightly over the course of the experiment in a linear manner. Based on the definition of relative supersaturation $\Sigma$ for $\alpha-\mathrm{HH}$, given by Equation 2, where $a$ represents the ion activities, this method of reagent addition resulted in nearly constant supersaturation 10 min after the pump was switched on. The evolution of $\Sigma$ over time can be seen from Figure 1. As it can be evaluated the supersaturation line remained practically flat especially over the period 20-60 min. This is a satisfactory regulation of supersaturation despite not using a feed-back control system as done in other studies [4] given the non-availability of corrosion-resistant probes for the current highly corrosive crystallization solution. The required equilibrium concentrations and the activity coefficients necessary for the calculation of the relative supersaturation were modeled with the help of the thermodynamic modeling software package OLI Stream Analyzer 3.2 [38].

$$
\Sigma=\frac{a_{\mathrm{Ca}^{2+}} a_{\mathrm{SO}_{4}^{2-}} a_{\mathrm{H}_{2} \mathrm{O}}^{0.5}}{\left(a_{\mathrm{Ca}^{2+}} a_{\mathrm{SO}_{4}^{2-}} a_{\mathrm{H}_{2} \mathrm{O}}^{0.5}\right)_{\mathrm{eq}}}-1
$$

Since the influence of different parameters such as temperature, reagent inflow and specific power 
input of agitation were varied certain default values were applied to the non-varied parameters in each test. These conditions are summarized in Table 1 and Table 2 . The default temperature was set at $80^{\circ} \mathrm{C}$, which ensures the metastability of the $\alpha-\mathrm{HH}$ phase [19] for the duration of the experiment. It was ensured via XRD characterization that no phase transformation occurred at the other temperatures tested. The stirring rate and hence the specific power input, were set to a value of $0.16 \mathrm{~W} / \mathrm{kg}$, which is suitable to obtain turbulent mixing conditions as further detailed by the calculations in the Appendix.

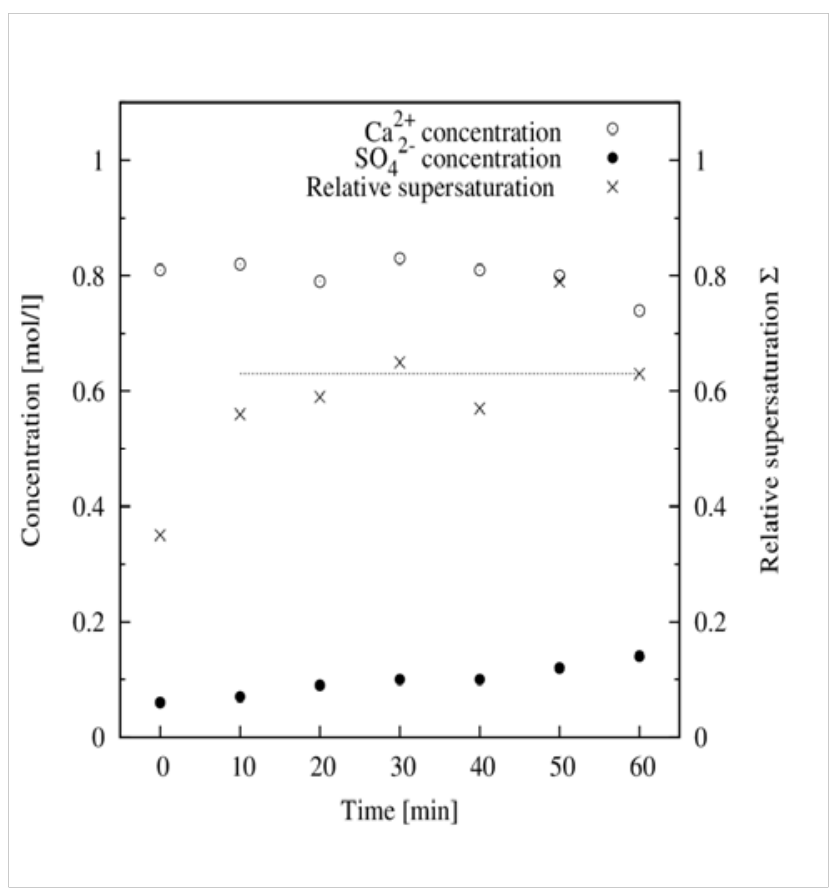

Figure 1: Typical evolution of calcium and sulfate ion concentration and resulting relative supersaturation during a semi-batch crystal growth experiment. Example: high $\mathrm{HCl}$ condition, $T=80^{\circ} \mathrm{C}$, specific power input $=0.16 \mathrm{~W} / \mathrm{kg}$, molar inflow rate $=0.3 \mathrm{~mol} / \mathrm{h}$

In terms of solution composition two reference scenarios were chosen a high $\mathrm{CaCl}_{2}$ condition representing the first stage of a continuous acid regeneration process and a high $\mathrm{HCl}$ condition representing the solution composition obtained during the end of the regeneration process [21]. The specific solution composition values representing the two conditions can be found in Table 1.

The crystal growth tests were carried out in the presence of seed. Since the morphology of calcium sulfate crystals depends on the starting seed material [39] it was decided to use $\alpha$-HH crystals produced in a similar way the growth tests were conducted. The seed production procedure developed previously in our laboratory [19] involved drop wise addition of $500 \mathrm{~mL}$ of $6.4 \mathrm{~mol} / \mathrm{L}$ sulfuric acid solution to $1 \mathrm{~L}$ of $4.0 \mathrm{~mol} / \mathrm{L} \mathrm{CaCl}_{2}$ solution at $80^{\circ} \mathrm{C}$ over 4 hours with an additional equilibration time of 1 hour.

As per XRD and DSC data presented in Figure 2 it can be seen that the lab-made seed material belongs to the $\alpha$-form of calcium sulfate hemihydrate when compared to industrial $\alpha$-HH reference material. Despite its weaker intensity in comparison to that of the commercial product the characteristic exothermic peak in the DSC trace that distinguishes the alpha and beta HH varieties [40-42] can be clearly seen. 
Table 1: Default experimental conditions employed during the semi-batch crystallization tests simulating the first (High $\mathrm{CaCl}_{2}$ condition) and final stage (High $\mathrm{HCl}$ condition) of a continuous four stage hydrochloric acid regeneration process

\begin{tabular}{lcc}
\hline Parameter [Unit] & High $\mathbf{C a C l}_{2}$ condition & High HCl condition \\
\hline Temperature $\left[{ }^{\circ} \mathrm{C}\right]$ & 80 & 80 \\
Specific power input stirring [W/kg] & 0.16 & 0.16 \\
Duration of experiment [min] & 60 & 60 \\
Initial volume of solution [ml] & 1000 & 1000 \\
Initial concentration of $\mathrm{CaCl} 2[\mathrm{~mol} / \mathrm{L}]$ & 2.8 & 0.7 \\
Initial concentration of $\mathrm{HCl}[\mathrm{mol} / \mathrm{L}]$ & 1.4 & 5.6 \\
\hline
\end{tabular}

In typical batch reactor growth rate studies, the change in solute concentration is used to derive the growth rate. Since in the present semi-batch reactor study, supersaturation is kept nearly constant an alternative method had to be used based on measurements of the change of particle size over time. This is a rather direct method of crystal growth rate derivation better reflecting the crystal evolution than the indirect solution composition method does. For the calculation of the growth rate the measured particle size distributions were modeled by fitting a log-normal probability distribution function (Equation 3), which is suitable to describe particle size distributions [43].

$$
f(x)=\frac{1}{x \sigma \sqrt{2 \pi}} e^{\frac{(\ln x-\mu)^{2}}{2 \sigma^{2}}}
$$

The parameters $\mu$ and $\sigma$ of the fitted distribution were subsequently used to calculate the mode of the distribution as a measure of the characteristic length of the particles. The change of this length over time gives the growth rate. The calculation of the mode was done for each of the five samples taken from a single experiment and regressed against time with a linear function. The slope of this function represents the change in particle size with time and hence the growth rate. This approach is schematically described in Figure 3.

Finally recognizing that crystal growth predominantly takes place at active surface sites, the measured growth rates had to be made independent of the specific surface area available for growth. This was done by taking into account the initial surface area of the seed crystals. The average surface area of the seed material was $0.548 \pm 0.072 \mathrm{~m}^{2} / \mathrm{g}$, which is slightly higher compared to surface area values of hemihydrate formed by conversion of dihydrate [44]. 

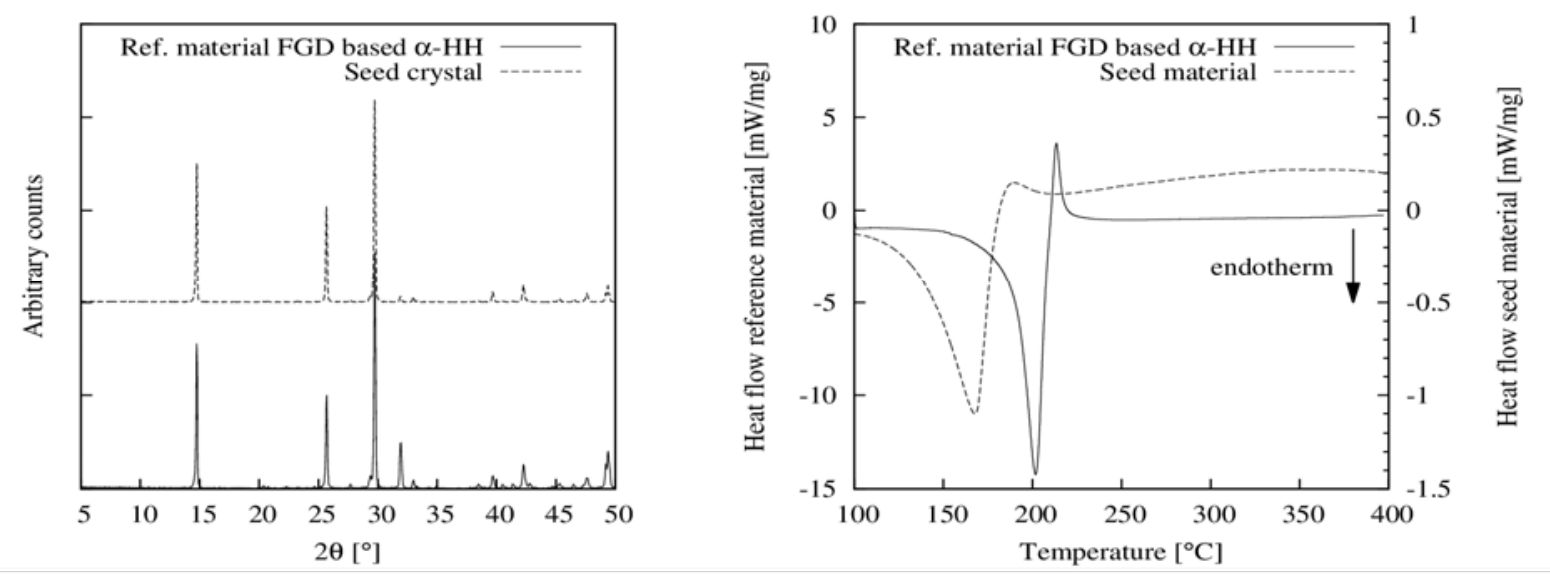

Figure 2: Characterization of produced $\alpha-H H$ seed material by XRD and DSC
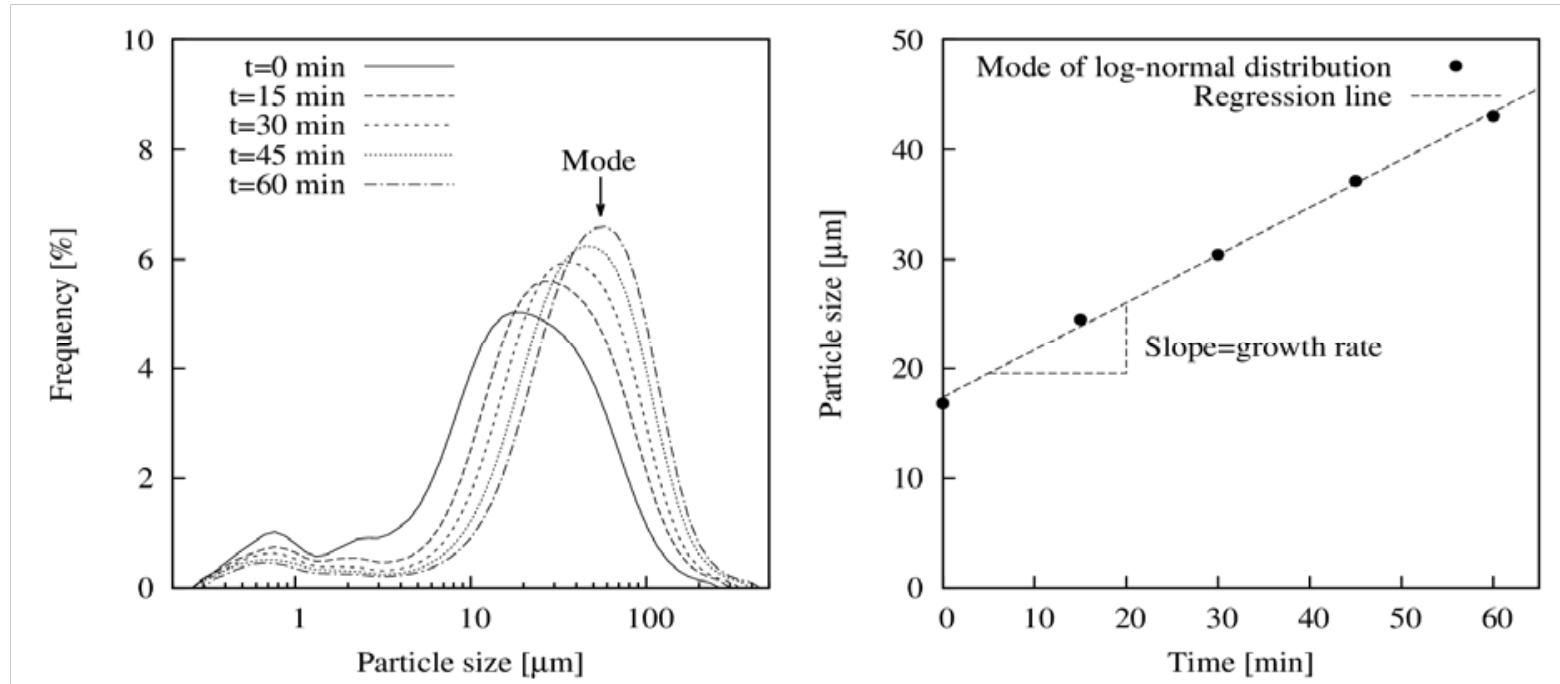

Figure 3: Schematic representation of the derivation of the crystal growth rate from measured particle size distribution data. Example: high $\mathrm{CaCl}_{2}$ condition, $\mathrm{T}=80^{\circ} \mathrm{C}$, specific power input $=0.16 \mathrm{~W} / \mathrm{kg}$, molar inflow rate $=0.3 \mathrm{~mol} / \mathrm{h}$

\subsection{Process parameter effects on crystal growth rate}

\subsubsection{Influence of reagent inflow rate - supersaturation level}

In the employed semi-batch experimental procedure the supersaturation level of the system was varied by adjusting the inflow rate. The range of values investigated is provided in Table 2 . Figure 4 shows the evolution of crystal size distribution (CSD) and crystal growth rate as a function of the reagent inflow rate. By increasing the inflow rate a progressively coarser and narrower size distribution is obtained (see Figure 4 (left)) opening in principle the opportunity for crystal size control via inflow rate regulation as has been done in other crystallization systems [45]. The increase in growth rate with inflow rate is not however monotonic. Thus an increase of the reagent inflow rate from 0 to $0.3 \mathrm{~mol} / \mathrm{h}$ resulted in a linear increase of the crystal growth rate, thereafter reaching a maximum at $0.3 \mathrm{~mol} / \mathrm{h}$. Until the maximum is reached the growth rate obeys the linear relationship given by Equation 4; where 
$\dot{m}$ represents the molar inflow rate in $\mathrm{mol} / \mathrm{h}, A$ the surface area in $\mathrm{m}^{2}, d L / d t$ represents the change in the mode of the particle size distribution with time in $\mathrm{nm} / \mathrm{min}, k$ is the slope and $C$ is a constant. As can be seen from the data in Table 3 the slope of the function is slightly higher for the high $\mathrm{HCl}$ condition, compared to the high $\mathrm{CaCl}_{2}$ condition.

$$
r=\frac{d L}{d t} \frac{1}{A}=k \dot{m}+C
$$

The determined linear relationship in the present work is in some disagreement with that obtained by Yang et al. [29], who investigated the $\mathrm{HH}$ growth rate in batch experiments with solutions containing $\mathrm{CaCl}_{2}$ as well as $\mathrm{MgCl}_{2}$ and/or $\mathrm{KCl}$ but not $\mathrm{HCl}$. These authors found that the order $n$ of the growth rate law (Equation 5) in solutions containing $3.74 \mathrm{~mol} / \mathrm{L} \mathrm{CaCl}_{2}$ (in the absence of magnesium and potassium ions) was 1.61. In Equation 5, $d C$ represents the change in concentration and $\Sigma$ the relative supersaturation, $k, A$ and $d t$ are defined as above. The same authors also found that the order of the process depended strongly on the presence of $\mathrm{Mg}^{2+}$ and $\mathrm{K}^{+}$and could be as low as 1.39 for certain conditions. This was explained by adsorption of these impurities to the crystal surface, slowing down the growth process.

$$
r=-\frac{1}{A} \frac{d C}{d t}=k \Sigma^{n}
$$

As a result, for certain conditions the growth process was closer to being of linear nature rather than of parabolic, which was the general conclusion of the authors. Hence, the results obtained in the current study, where the concentration of $\mathrm{H}^{+}$ions was much higher, provide a different chemical background in which the growth process takes place. It is postulated that high concentrations of protons influence the growth process in a similar way as they influence the speed of phase transformation between calcium sulfate phases [46]. Therefore it is concluded that in acidic chloride solutions the growth of $\alpha-\mathrm{HH}$ occurs predominantly via a mass transport or adsorption controlled process [47] in the range 0 to 0.3 $\mathrm{mol} / \mathrm{h}$ reagent inflow (or $\Sigma$ from 0 to 0.63 ).

Table 2: Variation of experimental parameters

\begin{tabular}{ll}
\hline Parameter [Unit] & Variation range \\
\hline Molar reagent inflow rate $[\mathrm{mol} / \mathrm{h}]$ & $0,0.05,0.1,0.2,0.25,0.3,0.4,0.6$ \\
Temperature $\left[{ }^{\circ} \mathrm{C}\right]$ & $70,75,80,85,90,95$ \\
Specific power input $[\mathrm{W} / \mathrm{kg}]$ & $0.02,0.07,0.16,0.54,1.29$ \\
\hline
\end{tabular}

Table 3: Parameters of fitted linear growth rate functions for the range of molar inflow rate from 0 to $0.3 \mathrm{~mol} / \mathrm{h}$

\begin{tabular}{lll}
\hline Parameter & High $\mathbf{C a C l}_{2}$ condition & High HCl condition \\
\hline$k$ & 5.53 & 7.17 \\
$C$ & 3.67 & -2.44 \\
\hline
\end{tabular}



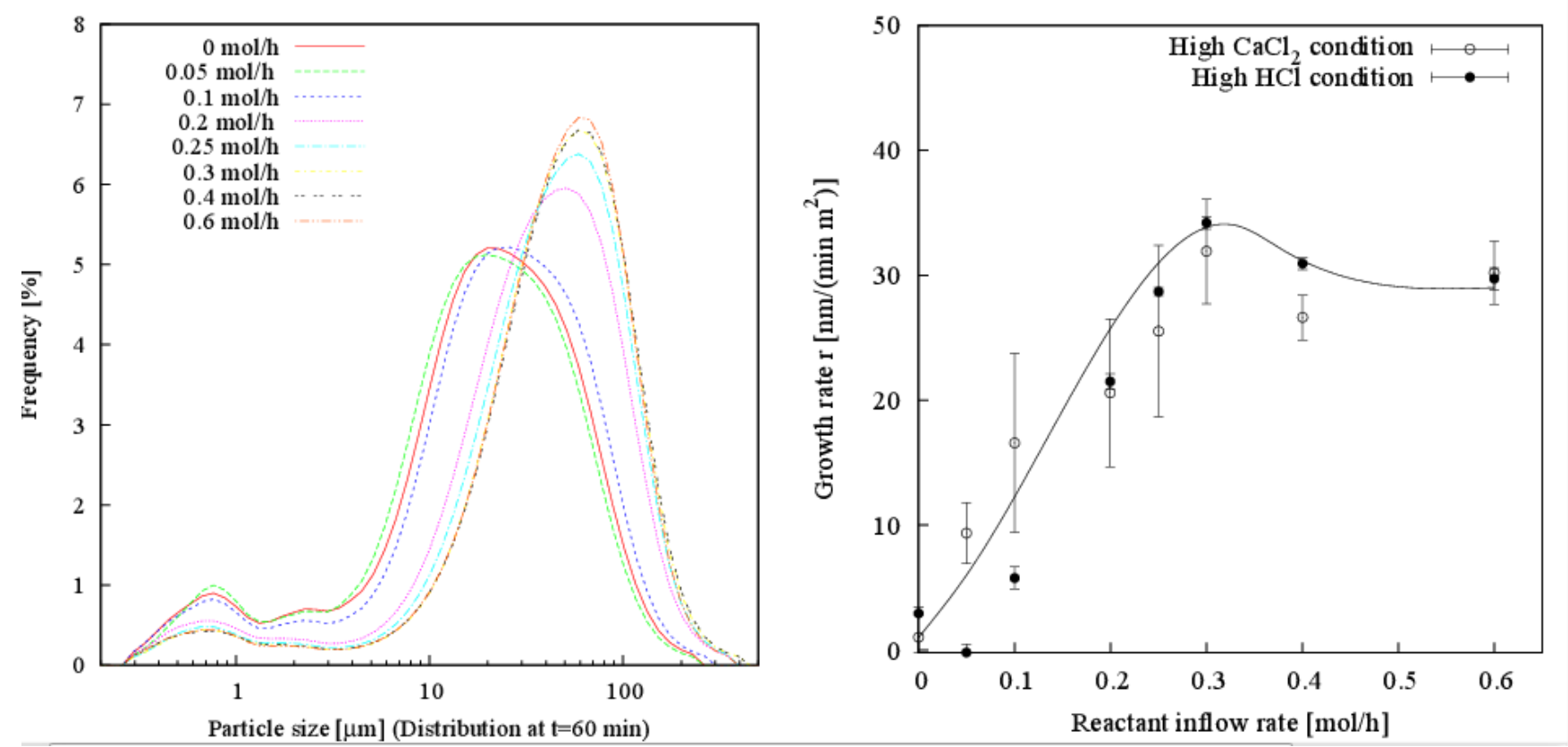

Figure 4: Influence of reagent inflow rate on crystal size distribution for high $\mathrm{HCl}$ condition (left) and growth rate for high $\mathrm{CaCl}_{2}$ and high $\mathrm{HCl}$ condition (right) at $\mathrm{T}=80^{\circ} \mathrm{C}$ and $0.16 \mathrm{~W} / \mathrm{kg}$ specific power input

At molar inflow rates above $0.3 \mathrm{~mol} / \mathrm{h}$ the growth rate decreases slightly before it plateaus. To put the overall behavior of growth rate with increasing supersaturation (molar inflow rate) into perspective, von Weimarn's second law may be recalled. This law, which was first described in the early twentieth century and later confirmed by experiments and theoretically [48-50], states that for a given crystallization time the average particle size passes through a maximum as a function of initial supersaturation [50]. In the present study the employed mode of reagent inflow resulted in a nearly constant supersaturation environment that is comparable with the initial supersaturation situation in a batch experiment. As a consequence a variation of the inflow rate represents the influence of different initial supersaturation levels; hence explaining the observed behavior of the growth rate as a function of $\dot{m}$ in the range $0-0.6 \mathrm{~mol} / \mathrm{h}$.

\subsubsection{Influence of specific power input of stirring}

In the case of diffusion controlled processes changes in the stirring rate, which can be conveniently expressed in terms of the specific power input, should influence the measured crystal growth rate [51]. Figure 5 shows for a molar inflow rate of $0.3 \mathrm{~mol} / \mathrm{h}$ and a temperature of $80^{\circ} \mathrm{C}$ that the specific power input did not have any noticeable effect on the crystal growth rate within the range of investigated conditions. This behavior is attributed to the turbulent flow regime that characterized the experimental conditions under which the growth of $\alpha-\mathrm{HH}$ crystals was studied. The presence of strong turbulent flow regime was confirmed by the calculation of the corresponding Reynolds numbers; the calculation procedure and results are given in the Appendix (Table 4). These turbulent flow conditions most likely resulted in a reduction of the diffusion boundary layer down to its limiting thickness hence the lack of a noticeable influence upon changing the stirring speed. 


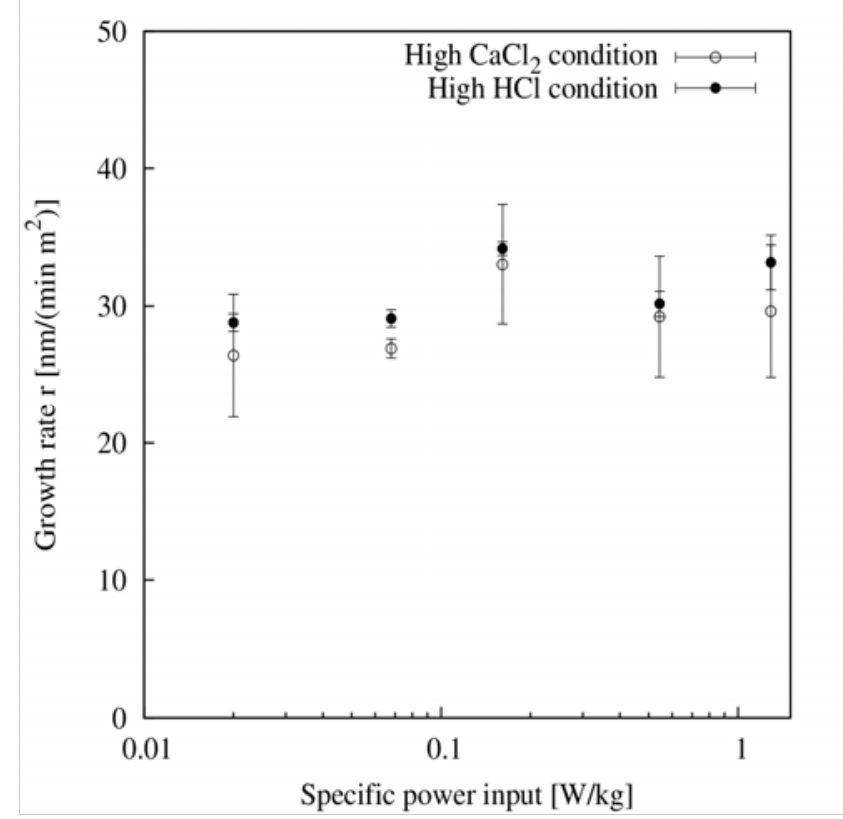

Figure 5: Influence of specific power input of stirring on the crystal growth rate at $80^{\circ} \mathrm{C}$ temperature and $0.3 \mathrm{~mol} / \mathrm{h}$ reagent inflow

\subsubsection{Influence of temperature}

In case of a reaction controlled process, changes of reaction temperature influence drastically the rate of crystal growth [52]. Figure 6 shows for a reagent inflow rate of $0.3 \mathrm{~mol} / \mathrm{h}$ and a specific energy input of $0.16 \mathrm{~W} / \mathrm{kg}$ no distinct influence of temperature on the crystal growth rate for the conditions of high or low $\mathrm{CaCl}_{2} / \mathrm{HCl}$ concentration in the background solution. However, a higher growth rate is seen in the case of high $\mathrm{HCl}$ condition compared to the high $\mathrm{CaCl}_{2}$ condition. The average growth rate for the high $\mathrm{HCl}$ condition is with $34.6 \mathrm{~nm} / \mathrm{min} \cdot \mathrm{m}^{2}$ noticeably higher compared to the high $\mathrm{CaCl}_{2}$ condition with an average growth rate of $27.3 \mathrm{~nm} / \mathrm{min} \cdot \mathrm{m}^{2}$. The higher growth rate in the high $\mathrm{HCl}$ condition could be explained by the approximately $30 \%$ lower viscosity $(6.9 \mathrm{mPa} \cdot \mathrm{s})^{1}$ of this solution compared to that of the high $\mathrm{CaCl}_{2}$ condition (9.6 $\left.\mathrm{mPa} \cdot \mathrm{s}\right)$. As Sha et al. [53] have shown, in the case of crystallization of potassium sulfate, a lower viscosity can lead to a higher crystal growth rate. In their case an increase in solution viscosity from $1.2 \mathrm{mPa} \cdot \mathrm{s}$ to $4.7 \mathrm{mPa} \cdot \mathrm{s}$ (3.9 times) resulted in a decrease of the growth rate by $72 \%$.

Based on the evidence presented above the crystal growth of $\alpha-\mathrm{HH}$ is concluded to be a diffusion controlled linear process under the investigated conditions.

${ }^{1}$ Viscosities were calculated with OLI Stream Analyzer 3.2 [38] 


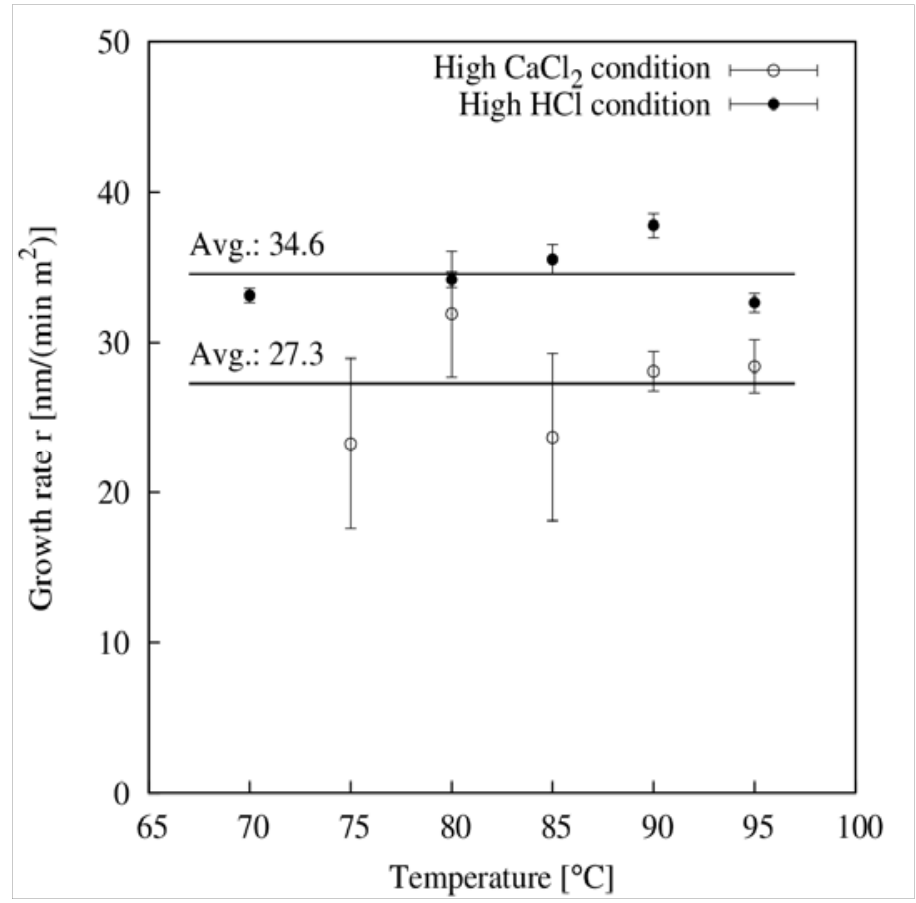

Figure 6: Influence of temperature on the crystal growth rate at $0.16 \mathrm{~W} / \mathrm{kg}$ specific power input and 0.3 $\mathrm{mol} / \mathrm{h}$ reagent inflow

\subsection{Effect of crystal growth rate on the width of particle size distribution}

For successful operation of the hydrochloric acid regeneration process the solid/liquid separation unit operation plays a crucial role. The width of the particle size distribution is a key performance criterion influencing the performance of the crystal separation/harvesting process [54]. Similarly the crystal size distribution is important from the standpoint of use of $\alpha-\mathrm{HH}$ as plaster/construction material. As it can be seen in Figure 7 a positive correlation exists between the width reduction of the particle size distribution and the crystal growth rate. Higher growth rates led to narrower distributions. The change in the width of the distribution $\Delta \sigma$ was defined as the difference of the parameter $\sigma$ of the log-normal probability distribution function fitted to the particle size distribution at the beginning and the end of each experiment. The more positive the $\Delta \sigma$ value the narrower the size distribution became. 


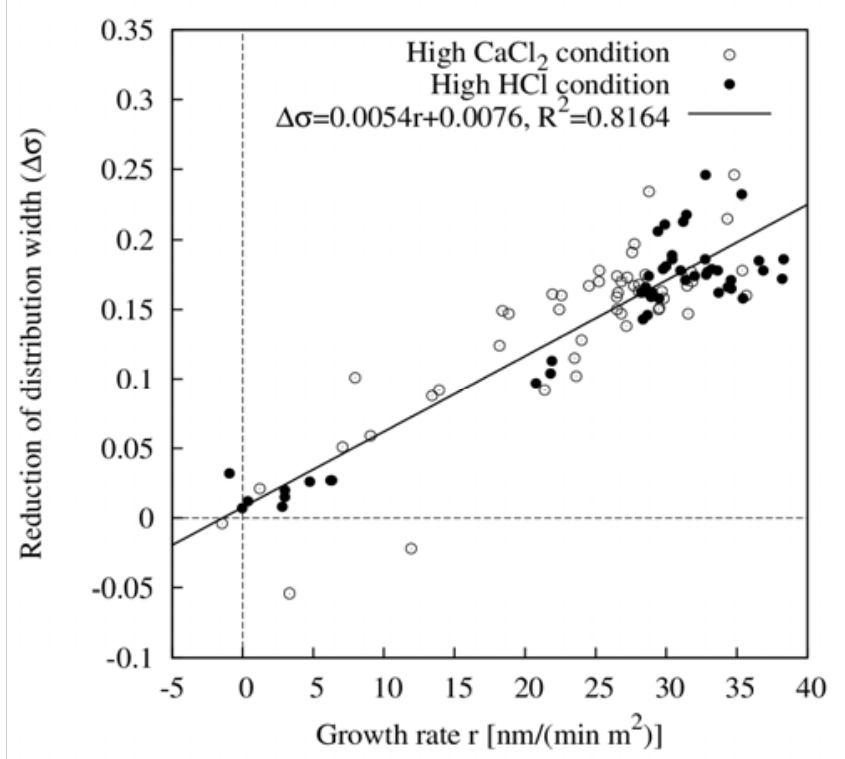

Figure 7: Correlation between the reduction of particle size distribution width and the crystal growth rate

This result is consistent with a size-dependent growth behavior, i.e., the growth rate of individual crystals varies according to their size and active site number or type of crystal plane [55]. Overall judging from the evolution of the size distributions plotted in Figure 3 it is noted that the frequency of fine ( $<10$ microns) crystals $^{2}$ decreases and the width of crystal size distribution (CSD) becomes narrower with time. Upon closer evaluation of the CSD in Figure 3 it can be seen the seed material to exhibit a modest bimodal pattern that incorporates a sub-micron size fraction. The frequency of this fraction decreases with time of crystal growth due to apparent ripening arising from size-dependent solubility [56,57]. The origin of the reduced frequency of crystals in the 1-10 microns range is less clear. Although size-dependent ripening appears unlikely other factors affecting growth/dissolution rates, such as defects at the crystal surface may be responsible in this case [58]. The following SEM and DSC characterization section provides indeed such evidence of crystal imperfection for the seed material (produced via homogeneous nucleation) that is progressively eliminated upon constant supersaturation-driven growth. Furthermore the narrowing of the size distribution may not simply be due to dissolution of the small crystals but rather arise from the "law of proportionate effect" that dictates faster growth of the larger crystals than the corresponding smaller ones [58,59]. As such, the relative fraction (frequency in Figure 3) of the smaller crystals decreases vis-á-vis that of the larger ones hence the narrowing of the CSD. Note that the mass of crystals keeps increasing in this growth experiment as opposed to near equilibrium ripening of a constant mass of crystals. Finally, it is interesting to note that Sha et al. [60] and Tai et al. [61], who studied the growth kinetics of $\mathrm{K}_{2} \mathrm{SO}_{4}$ and $\mathrm{CaCO}_{3}$ crystals respectively, observed a dramatically stronger size-dependent growth rate above $10 \mu \mathrm{m}$ as also noted in this work-refer to Figure 3.

${ }^{2}$ Note that if the disappearance of the fine crystals were associated with experimental handling involving temperature fluctuations during sampling then this would have resulted in particular to dissolution of the sub-micron fines found in the homogeneously produced $\left(\right.$ at $80^{\circ} \mathrm{C}$ ) seed material (refer to Figure 3), which obviously was not the case. 


\subsection{Crystal quality of $\alpha$-calcium sulfate hemihydrate}

The evolution of the crystal size and morphology can be better appreciated by resorting to SEM examination. As it can be deduced from the SEM images presented in Figures 8 and 9 there was no major change in the $\alpha$-hemihydrate crystal morphology upon growth for either crystallization condition. The crystals exhibit the typical acicular shape of $\alpha-\mathrm{HH}$ formed in aqueous media. However, upon growth the crystals become increasingly longer and thicker assuming very well developed crystal planes as evident in the high magnification SEM picture of Figure 10. Overall the aspect ratio of the grown crystals, defined as length to width, ranged from 5 to 17 and was on average 10.5 . This value is considerably higher than that for hemihydrate, which is produced by the conversion of dihydrate in salt solution [62]. There was no obvious change in the ratio with change of the experimental conditions. This is in contrast to findings of Wang et al. [62], who found significant changes in the length to width ratio of $\alpha-\mathrm{HH}$, which was produced by dehydration of calcium sulfate dihydrate in variable concentration calcium chloride solutions but in the absence of $\mathrm{HCl}$ acid. Finally it is worthy to note that seeded crystallization at constant supersaturation led further to enhancing the alpha structure of hemihydrate as evidenced by the DSC curves of Figure 11. Thus as it can be seen the exothermic peak of the grown crystals (at $\mathrm{t}=60 \mathrm{~min}$ ), that characterizes $\alpha-\mathrm{HH}$, is noticeably more pronounced than that of the seed material. This effect can be explained by a combined effect of increased crystal size and surface smoothness. The healing of surface defects leads to a reduced specific surface area, which results in a more pronounced exothermic peak [63]. The same effect has been reported for $\alpha-\mathrm{HH}$ produced by conversion of $\mathrm{DH}$ in $\mathrm{CaCl}_{2}$ solution and attributed to an increase in crystal size [64]. Finally it appears that growth under high acid condition led to better quality $\alpha-\mathrm{HH}$ crystals as evident by the highest exothermic peak intensity (see Figure 11). Therefore production of $\alpha-\mathrm{HH}$ under acid regeneration conditions is expected to lead to improved crystal quality.
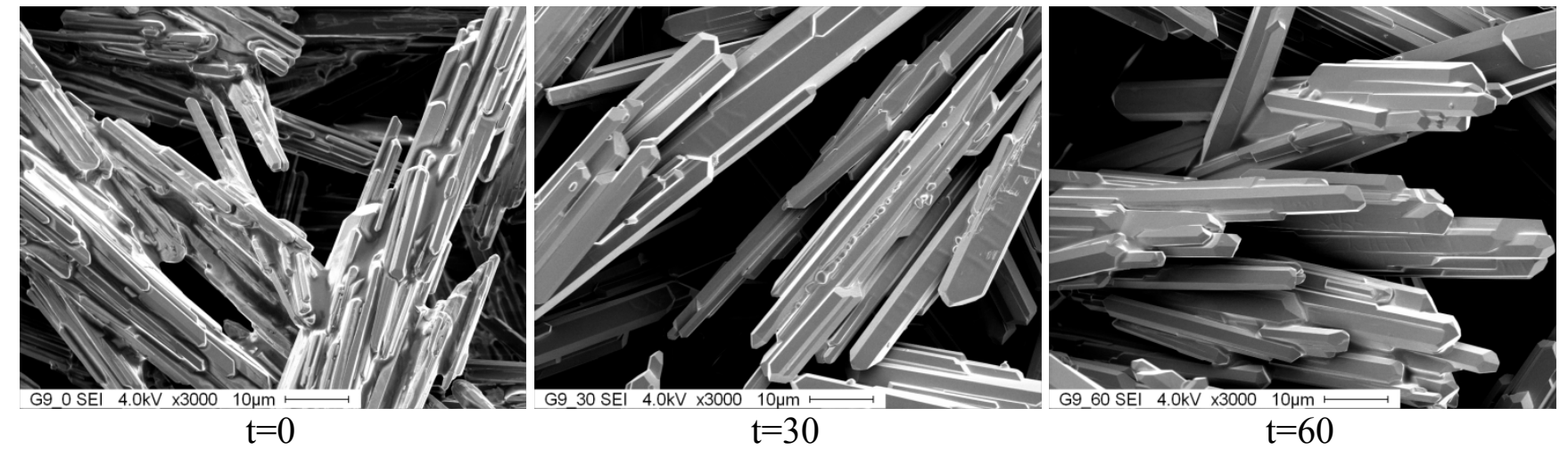

Figure 8: Calcium sulfate $\alpha$-hemihydrate crystal morphology at different times with $0.3 \mathrm{~mol} / \mathrm{h}$ reagent inflow, $80^{\circ} \mathrm{C}$ temperature and $0.16 \mathrm{~W} / \mathrm{kg}$ specific power input under high $\mathrm{CaCl}_{2}$ concentration condition 


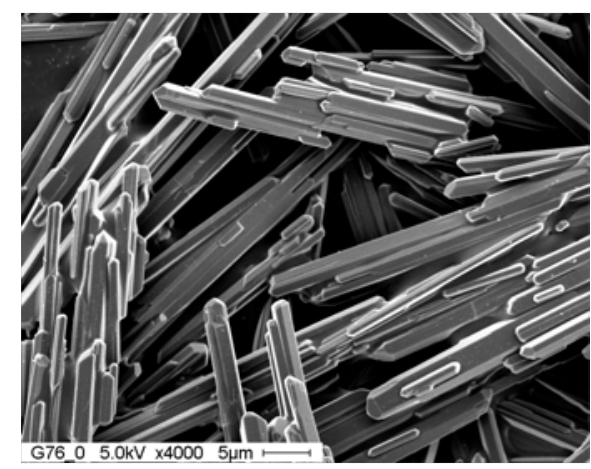

$\mathrm{t}=0 \mathrm{~min}$

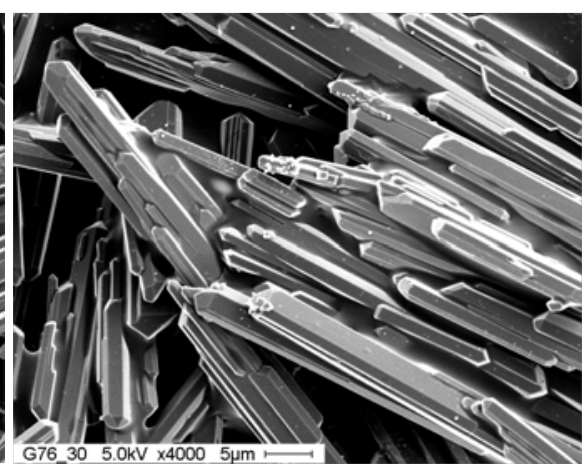

$\mathrm{t}=30 \mathrm{~min}$

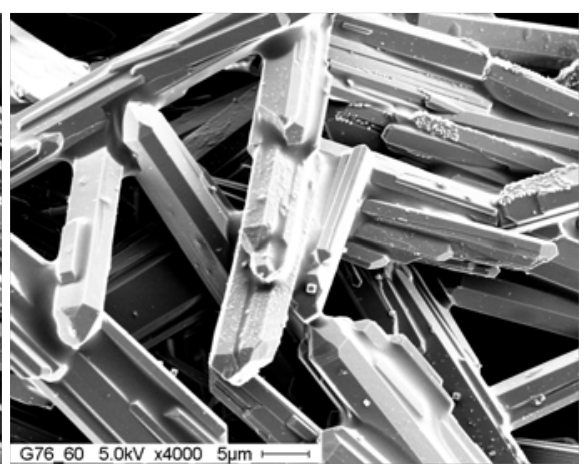

$\mathrm{t}=60 \mathrm{~min}$

Figure 9: Calcium sulfate $\alpha$-hemihydrate crystal morphology at different times with $0.3 \mathrm{~mol} / \mathrm{h}$ reagent inflow, $80^{\circ} \mathrm{C}$ temperature and $0.16 \mathrm{~W} / \mathrm{kg}$ specific power input under high $\mathrm{HCl}$ concentration condition

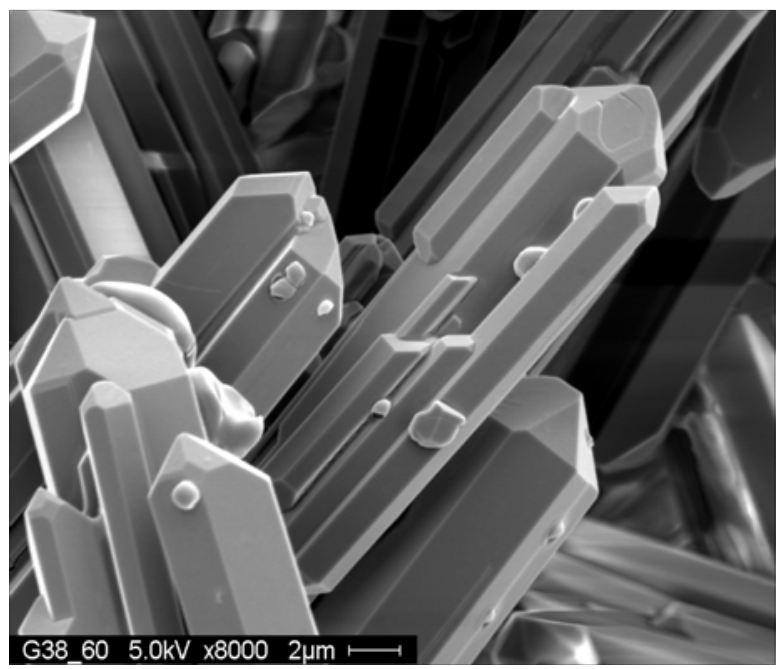

Figure 10: Detailed features of well grown calcium sulfate $\alpha$-hemihydrate crystals produced at 0.3 mol/h reagent inflow, $90^{\circ} \mathrm{C}$, and $0.16 \mathrm{~W} / \mathrm{kg}$ specific power input under high $\mathrm{CaCl}_{2}$ concentration condition after 1 h of experiment 


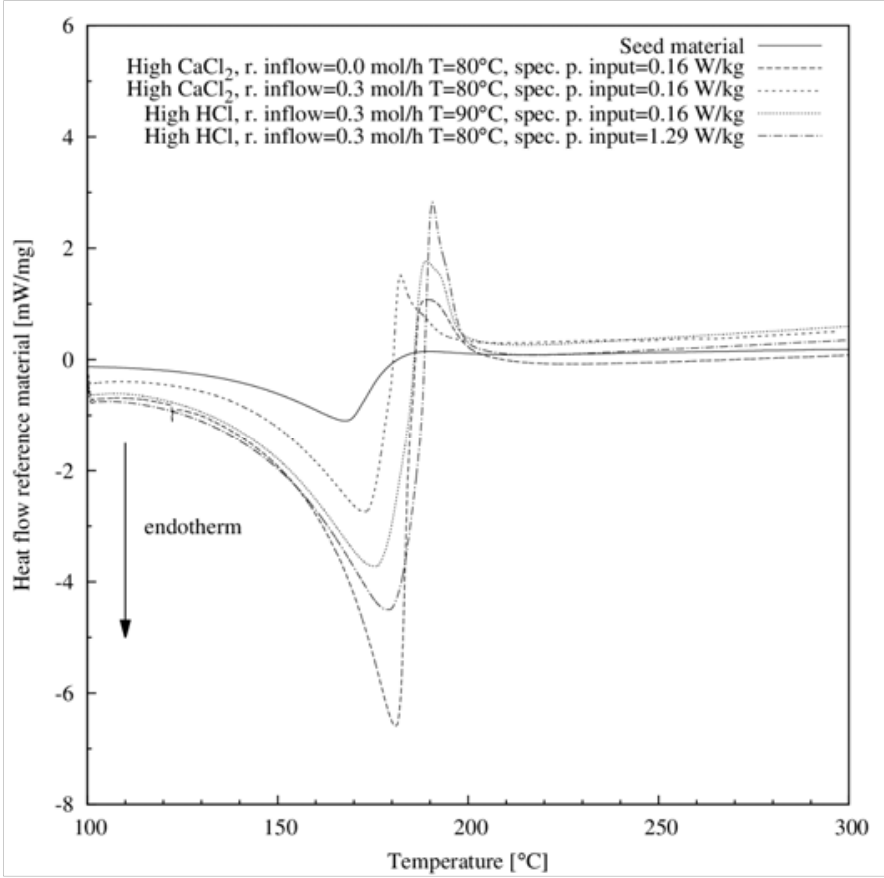

Figure 11: DSC analysis of $\alpha-H H$ materials obtained via seeded crystallization showing improvement over initial seed material

\section{Conclusions}

The crystal growth kinetics of $\alpha$-calcium sulfate hemihydrate in seeded constant supersaturation $\mathrm{CaCl}_{2}-$ $\mathrm{HCl}$ solutions was investigated in the context of a new hydrochloric acid regeneration process. It is the first time such a study is undertaken involving high $\mathrm{HCl}$ concentration solutions. The study was carried over the temperature range $70-95^{\circ} \mathrm{C}$. Constant supersaturation was maintained via semi-batch reaction of sodium sulfate with $\mathrm{CaCl}_{2}$ within $\mathrm{CaCl}_{2}(2.8 \mathrm{~mol} / \mathrm{L}$ or $0.7 \mathrm{~mol} / \mathrm{L})-\mathrm{HCl}(1.4 \mathrm{~mol} / \mathrm{L}$ or $5.6 \mathrm{~mol} / \mathrm{L})$ solutions. The major conclusions are:

1. The crystal growth rate is linearly related to the inflow rate of reagents (which in turn relates to governing supersaturation) with the optimal value obtained at $0.3 \mathrm{~mol} / \mathrm{h}(\Sigma=0.6)$. At this inflow rate the mass of produced $\alpha-\mathrm{HH}$ crystals corresponds to approximately $150 \%$ of the initial mass of seed crystals.

2. The growth rate was derived from measurements of the particle size distribution as a function of time. The growth rate was found within the range of conditions investigated to be essentially independent of stirring rate and temperature. This behavior combined with the observed linear growth relationship is attributed to a diffusion-controlled process through the limiting thickness boundary layer imposed by the prevailing strong turbulent flow regime.

3. The overall crystal growth process was found further to follow the von Weimarn law of crystallization, which correlates the particle size with the supersaturation level. Since supersaturation can be regulated via the adjustment of the reagent inflow rate, this implies that the latter can be used to control the resultant crystal size distribution.

4. The width of the particle size distribution was found to decrease with increasing crystal growth 
rate; this behavior is attributed to a size-dependent growth process.

5. The quality of the acicular $\alpha$-hemihydrate crystals was found to improve not only in terms of crystal size and aspect ratio but also in its alpha crystal structure as evidenced by DSC analysis hence making the production of a value-added plaster material under acid regeneration conditions possible.

\section{Acknowledgments}

The financial support of Arafura Resources Ltd. for this research project is gratefully acknowledged as well as the donation of the $\alpha$-calcium sulfate hemihydrate reference material by Knauf Gips KG.

\section{References}

[1] A.N. Christensen, T.R. Jensen, A. Nonat, A new calcium sulfate hemi-hydrate, Dalton Trans. 39 (2010) 2044-2048.

[2] B. Guan, Q. Ye, Z. Wu, W. Lou, L. Yang, Analysis of the relationship between particle size distribution of $\alpha$-calcium sulfate hemihydrate and compressive strength of set plaster - Using grey model, Powder Technol. 200 (2010) 136-143.

[3] Q. Ye, B. Guan, W. Lou, L. Yang, B. Kong, Effect of particle size distribution on the hydration and compressive strength development of $\alpha$-calcium sulfate hemihydrate paste, Powder Technol. 207 (2011) 208-214.

[4] N.C.S. Kee, R.B.H. Tan, R.D. Braatz, Selective crystallization of the metastable $\alpha$-form of Lglutamatic acid using concentration feedback control, Crys. Growth Des. 9 (2009) 3044-3051.

[5] A.J. Lewry, J. Williamson, The setting of gypsum plaster - Part II The development of microstructure and strength, J. Mater. Sci. 29 (1994) 5524-5528.

[6] A. Duda, T. Koslowski, New products from FGD gypsum, VGB Kraftwerkstechnik 11 (1991) 938943.

[7] R. Kwasny-Echterhagen, H. Schlieper, G. Kirchen, H. Morgenroth, G. Wiesgickl, Alphahemihydrate - A high value building material made from FGD gypsum, experiences concerning processing, product development and market applications. In: Proceedings of the 5th International Conference on FGD and Synthetic Gypsum, May 1997, (1997) ORTECH, pp. 8-1 - 8-15.

[8] SICOWA Verfahrenstechnik für Baustoffe, Verfahren zur Herstellung von praktisch phasenreinem Calciumsulfat-Alpha-Halbhydrat, Patent: Germany DE 19737778 A1 (1999).

[9] W. Hohmann, Method and arrangement for producing $\alpha$-calcium sulfate hemihydrate using the gypsum suspension produced during the wet flue gas desulfurization of a fossil-fired thermal power station, Patent: World WO 00/48958 (2000).

[10] J. Bold, F. Fink, J. Umlauf, Process for the conversion of calcium sulfate dihydrate into alphahemihydrate, Patent: United States US 5,248,487 (1993).

[11] A. Kostic-Pulek, S. Marinkovic, S. Popov, R. Tomanec, Developing a hydrothermal technique for production of alpha-hemihydrate calcium-sulfate from flue gas gypsum, Ceram.-Silik. 40 (1996) 99102.

[12] A. Hina, G.H. Nancollas, Alpha calcium sulfate hemihydrate and a method of making alpha 
calcium sulfate hemihydrate, Patent: World WO 01/79116 A1 (2001).

[13] B. Guan, L. Yang, Z. Wu, Z. Shen, X. Ma, Q. Ye, Preparation of $\alpha$-calcium sulfate hemihydrate from FGD gypsum in $\mathrm{K}$, Mg-containing concentrated $\mathrm{CaCl}_{2}$ solution under mild conditions, Fuel 88 (2009) 1286-1293.

[14] A. Zürz, I. Odler, F. Thiemann, K. Berghöfer, Autoclave-free formation of alpha-hemihydrate gypsum, J. Am. Ceram. Soc. 74 (1991) 1117-1124.

[15] B. Guan, G. Jiang, Z. Wu, J. Mao, B. Kong, Preparation of $\alpha$-calcium sulfate hemihydrate from calcium sulfate dihydrate in methanol-water solution under mild conditions, J. Am. Ceram. Soc. 94 (2011) 3261-3266.

[16] J.W. College, Method of sulfur dioxide removal from gaseous streams with alpha-hemihydrate gypsum product formation, Patent: United States US 5,312,609 (1994).

[17] J.W. College, The Omega process. In: 6th International Conference on Natural and FGD Gypsum, May 16-19, 2000, Process Research ORTECH Inc. Mississauga Ontario Canada (2000).

[18] J.S. Berrie, G.E. Wooley, Manufacture of calcium sulfate alpha hemihydrate, Patent: United States US 4,120,737 (1978).

[19] S. Girgin, G.P. Demopoulos, Production of the high value material alpha-CaSO 4 hemihydrate out of spent $\mathrm{CaCl}_{2}$ solutions by reaction with $\mathrm{H}_{2} \mathrm{SO}_{4}$. In: Schlesinger, M. E. (Ed.), EPD Congress 2004, 2004, TMS (The Minerals, Metals \& Materials Society), Warrendale 2004 pp. 627-639.

[20] J.-C. Yang, H.-D. Wu, N.-C. Teng, S.-Y. Lee, Process for preparing alpha calcium sulfate hemihydrate, Patent: United States US 2010/0086474 A1 (2010).

[21] A.L. Al-Othman, G.P. Demopoulos, Gypsum crystallization and hydrochloric acid regeneration by reaction of calcium chloride solution with sulfuric acid. Hydrometallurgy 96 (2009) 95-102.

[22] G.P. Demopoulos, L. Zhibao, L. Becze, G. Moldoveanu, T.C. Cheng, B. Harris, New technologies for $\mathrm{HCl}$ regeneration in chloride hydrometallurgy. World of Metallurgy - Erzmetall 61 (2008) 89-98.

[23] Z. Li and G.P. Demopoulos, Model-based construction of calcium sulfate phase transition diagrams in the $\mathrm{HCl}-\mathrm{CaCl}_{2}-\mathrm{H}_{2} \mathrm{O}$ System between 0 and $100^{\circ} \mathrm{C}$, Ind. Eng. Chem. Res. 45 (2006) 45174524.

[24] S.-T. Liu, G.H. Nancollas, The kinetics of crystal growth of calcium sulfate dihydrate, J. Cryst. Growth 6 (1970) 281-289.

[25] G.H. Nancollas, M.M. Reddy, F. Tsai, Calcium sulfate dihydrate crystal growth in aqueous solution at elevated temperatures, J. Cryst. Growth 20 (1973) 125-134.

[26] G.J. Witkamp, J.P. van Der Eerden, G.M. van Rosmalen, Growth of gypsum I. Kinetics, J. Cryst. Growth 102 (1990) 281-289.

[27] M. El Moussaouiti, R. Boistelle, A. Bouhaouss, J.P. Klein, Agglomeration kinetics of calcium sulfate hemihydrate crystals in sulfo-phosphoric solutions, J. Cryst. Growth 169 (1996) 118-123.

[28] M. El Moussaouiti, R. Boistelle, A. Bouhaouss, J.P. Klein, Crystallization of calcium sulfate hemihydrate in concentrated phosphoric acid solutions, Chem. Eng. J. (Amsterdam, Neth.) 68 (1997) 123-130.

[29] L. Yang, Z. Wu, B. Guan, H. Fu, Q. Ye, Growth rate of $\alpha$-calcium sulfate hemihydrate in K-Ca$\mathrm{Mg}-\mathrm{Cl}-\mathrm{H}_{2} \mathrm{O}$ systems at elevated temperature, J. Cryst. Growth 311 (2009) 4518-4524. 
[30] Z. Li, G.P. Demopoulos, Solubility of $\mathrm{CaSO}_{4}$ Phases in Aqueous $\mathrm{HCl}+\mathrm{CaCl}_{2}$ Solutions from 283 K to 353 K, J. Chem. Eng. Data 50 (2005) 1971-1982.

[31] M. Barrett, M. McNamara, H. Hao, P. Barrett, B. Glennon, Supersaturation tracking for the development, optimization and control of crystallization processes, Chem. Eng. Res. and Des. 88 (2010) 1108-1119.

[32] C.Y. Ma, X.Z. Wang, Closed-loop control of crystal shape in cooling crystallization of L-glutamic acid, J. Proc. Cont. 22 (2012) 72-81.

[33] Z. Amjad, Constant composition study of crystal growth of calcium fluoride. Influence of poly(carboxylic acids), polyphosphates, phosphonates, and phytate, Langmuir 7 (1991) 600-603.

[34] J. Zhang, G.H. Nancollas, Influence of calcium/sulfate molar ratio on the growth rate of calcium sulfate dihydrate at constant supersaturation, J. Crys. Growth 118 (1992) 287-294.

[35] C.Y. Tai, M. Hon, P.-C. Chen, A comparison of growth behavior between $\mathrm{CaCO}_{3}$ and $\mathrm{CaF}_{2}$ crystals in a constant-composition environment, J. Taiwan Inst. Chem. Eng. 47 (2011) 435-440.

[36] P. Koutsoukos, Z. Amjad, M.B. Tomson, G.H. Nancollas, Crystallization of calcium phosphates. A constant composition study, J. Am. Chem. Soc. 102 (1980) 1553-1557.

[37] Y. Ling, G.P. Demopoulos, Preparation of $\alpha$-calcium sulfate hemihydrate by reaction of sulfuric acid with lime, Ind. Eng. Chem. Res. 44 (2005) 715-724.

[38] OLI Stream Analyzer, http://www.olisystems.com/new-streamanalyzer.shtml, accessed: December $5,2011$.

[39] G.P. Demopoulos, Aqueous precipitation and crystallization for the production of particulate solids with desired properties, Hydrometallurgy 96 (2009) 199-214.

[40] D.A. Powell, Transformation of the alpha- and beta-forms of calcium sulfate hemihydrate to insoluble anhydrite, Nature 182 (1958) 792.

[41] W.E.P. Fleck, M.H. Jones, R.A. Kuntze, H.G. McAdie, The differential thermal analysis of natural and synthetic hydrates of calcium sulfate, Can. J. Chem. 38 (1960) 936-943.

[42] B. Guan, X, Ma, Z. Wu, L. Yang, Z. Shen, Crystallization routes and metastability of $\alpha$-calcium sulfate hemihydrate in potassium chloride solutions under atmospheric pressure, J. Chem. Eng. Data 54 (2009) 719-725.

[43] H.G. Merkus, Particle size measurements, Springer 2009.

[44] M. Tang, X. Shen, H. Huang, Influence of $\alpha$-calcium sulfate hemihydrate particle characteristics on the performance of calcium sulfate-based medical materials, Mater. Sci. Eng., C 30 (2010) 11071111 .

[45] G.X. Zhou, M. Fujiwara, X.Y. Woo, E. Rusli, H.-H. Tung, C. Starbuck, O. Davidson, Z. Ge, R.D. Braatz, Direct design of pharmaceutical antisolvent crystallization through concentration control, Crys. Growth Des. 6 (2006) 892-898.

[46] G. Azimi, V.G. Papangelakis, Mechanism and kinetics of gypsum-anhydrite transformation in aqueous electrolyte solutions, Hydrometallurgy 108 (2010) 122-129.

[47] A.E. Nielsen, Theory of electrolyte crystal growth - The parabolic rate law, Pure Appl. Chem. 53 (1981) 2025-2039.

[48] P.P. von Weimarn, The precipitation laws, Chem. Rev. 2 (1925) 217-242. 
[49] J.W. Mullin, H.-M. Ang, Supersaturation and crystal size distribution changes during the precipitation of nickel ammonium sulfate hexahydrate, Kristall und Technik 12 (1977) 105-115.

[50] D.A. Barlow, J.K. Baird, C.-H. Su, Theory of the von Weimarn rules governing the average size of crystals precipitated from a supersaturated solution, J. Cryst. Growth 264 (2004) 417-423.

[51] J.A. Dirksen, T.A. Ring, Fundamentals of crystallization: Kinetic effects on particle size distributions and morphology, Chemical Engineering Science 46 (1991) 2389-2427.

[52] T. Havlik, Hydrometallurgy - Principles and Applications, Woodhead Publishing Ltd., 2006.

[53] Z. Sha, H. Alatalo, M. Louhi-Kultanen, S. Palosaari, Purification by crystallization from solutions of various viscosities, J. Cryst. Growth 198-199 (1999) 692-696.

[54] R. Wakeman, The influence of particle properties on filtration, Sep. Purif. Technol. 58 (2007) 234241.

[55] J.W. Mullin, Crystallization, fourth ed., Butterworth-Heinemann, 2001.

[56] T. Sugimoto, Preparation of monodispersed colloidal particles, Adv. Colloid Interfac. 28 (1987) 65-108.

[57] M. Iggland, M. Mazzotti, Population balance modeling with size-dependent solubility: Ostwald ripening, Cryst. Growth Des. 12 (2012) 1489-1500.

[58] B.J. McCoy, A new population balance model for crystal size distributions: Reversible, sizedependent growth and dissolution, J. Colloid Interface Sci. 240 (2001) 139-149.

[59] D.E. Kile, D.D. Eberl, On the origin of size-dependent and size-independent crystal growth: Influence of advection and diffusion, Am. Mineral. 88 (2003) 1514-1521.

[60] Z.L. Sha, H. Hatakka, M. Louhi-Kultanen, S. Palosaari, Crystallization kinetics of potassium sulfate in an MSMPR stirred crystallizer, J. Crys. Growth 166 (1996) 1105-1110.

[61] C.Y. Tai, P.-C. Chen, S.-M. Shih, Size-dependent growth and contact nucleation of calcite crystals AIChE J. 39 (1993) 1472-1482.

[62] P. Wang, E.-J. Lee, C.-S. Park, B.-H. Yoon, D.-S. Shin, H.-E. Kim, Y.-H. Koh, S.-H. Park, Calcium sulfate hemihydrate powders with a controlled morphology for use as bone cement, J. Am. Ceram. Soc. 91 (2008) 2039-2042.

[63] H. Lehmann, Die Phasenbeziehungen im System $\mathrm{CaSO}_{4}-\mathrm{H}_{2} \mathrm{O}$, Tonind.-Ztg. und Keramische Rundsch. 91 (1967) 6-12.

[64] J.-C. Yang, H.-D. Wu, N.-C. Teng, D.-Y. Ji, S.-Y. Lee, Novel attempts for the synthesis of calcium sulfate hydrates in calcium chloride solutions under atmospheric conditions, Ceram. Int. 38 (2012) 381-387.

[65] A. Mersmann, Crystallization technology handbook. Marcel Dekker, Inc., New York, 1995.

[66] E.L. Paul, V.A. Atiemo-Obeng, S.M. Kresta, Handbook of industrial mixing - science and practice. John Wiley \& Sons, 2004. 


\section{Appendix}

\section{Calculation of the specific power input of stirring}

For the experiments that determined the influence of the stirring speed on the growth rate of the crystals the actual rpm setting was converted into the specific power input $\varepsilon$. This allows to transfer the results to other experimental set ups with different dimensions. The specific power input was calculated according to Equation 6 [65].

$$
\varepsilon=\frac{4}{\pi} N_{P} N^{3} D^{2}\left(\frac{D}{T}\right)^{2} \frac{D}{H}
$$

$D$...stirrer diameter $(0.06 \mathrm{~m})$

$N$...stirrer speed (varied 150 to $600 \mathrm{rpm}$ )

$N_{P} \ldots$ power number

$T$...vessel diameter $(0.12 \mathrm{~m})$

$H$...useful height $(0.08 \mathrm{~m})$

The power number $N_{\boldsymbol{p}}$ was estimated to be constant at 1.5 based on the calculation of the Reynolds number and used stirrer type (type 6 in Fig. 6-14 from reference values given in the Handbook of Industrial Mixing [66]). The required viscosity and density values for the calculation of the Reynolds number determined with the help of the OLI Stream Analyzer 3.2 software [38] were $9.6 \mathrm{mPa} \cdot \mathrm{s}, 1.236$ $\mathrm{g} / \mathrm{cm}^{3}$ (high $\mathrm{CaCl}_{2}$ condition) and $6.9 \mathrm{mPa} \cdot \mathrm{s}, 1.126 \mathrm{~g} / \mathrm{cm}^{3}$ (high $\mathrm{HCl}$ condition) respectively. The calculation results are summarized in Table 4. As it can be seen for all conditions and rpm values the Reynolds number ( $\mathrm{Re}$ ) was above 10,000 , i.e. in the zone of turbulent flow. As shown in the Handbook of Industrial Mixing (Figure 6-14 on p. 361) [66] at $\mathrm{Re}>10,000$ the power number is constant, a situation that applies to the present experimental work.

Table 4: Conversion of stirrer speed into specific power input

\begin{tabular}{|c|c|c|c|}
\hline Stirrer speed & $\begin{array}{l}\text { Reynolds number for } \\
\text { high } \mathrm{CaCl}_{2} \text { condition }\end{array}$ & $\begin{array}{l}\text { Reynolds number } \\
\text { high HCl condition }\end{array}$ & for Specific power input \\
\hline $\min ^{-1}$ & & & $\mathrm{~W} / \mathrm{kg}$ \\
\hline 150 & 14559 & 14597 & 0.02 \\
\hline 225 & 21839 & 21895 & 0.07 \\
\hline 300 & 29119 & 29194 & 0.16 \\
\hline 450 & 43678 & 43791 & 0.54 \\
\hline 600 & 58238 & 58388 & 1.29 \\
\hline
\end{tabular}

